\title{
Blockbuster Architecture: From Jurassic Park to Millennium Park
}

\author{
By Acalya Allmer*
}

This study examines the pursuit of virtuosity, which culminates in the current practice of architecture with the intention to leave the spectator in a state of wonder at the skill and technical mastery that lies behind its construction. Focusing on Hollywood science-fiction films, it compares the special effects of the cinematic spectacles and technological advances displayed in the architecture of the late twentieth-and early twenty-first centuries. It argues that both produce work that aims to leave the spectator mesmerized in the methods used to construct these spectacles. As is discussed below, they strategically confront viewers with a technological tour de force.

'A faint crackling sound, like a fire in a fireplace. Something warm and wet tickled Grant's ankle. He opened his eyes and saw an enormous beige head.

The head tapered to a flat mouth shaped like the bill of a duck. The eyes, protruding above the flat duckbill, were gentle and soft like a cow's. The duck mouth opened and clewed branches on the limb where Grant was sitting. He saw large flat teeth in the cheek. The warm lips touched his ankle again as the animal chewed. A duckbilled hadrosaur. He was astonished to see it up close...,

\section{Introduction}

Above Michael Crichton, the author of the bestseller novel Jurassic Park, describes the close encounter of the paleontologist Alan Grant with a living dinosaur. The story is about genetically engineered dinosaurs brought to life and placed in a giant theme park on an island for the entertainment of its visitors. When Steven Spielberg produced the movie Jurassic Park in 1993, it was a great success and drew millions into the film theaters. However, it was not the dinosaurs that enthralled the spectators, but the computer effects that convincingly created the dinosaurs on the film screen. Computers played an important role in the virtuoso realization of the film leaving the spectators astonished at the unprecedented methods employed to make Jurassic Park possible.

Computer has been an important means of displaying and celebrating technological virtuosity in contemporary architecture as well. In recent years, we have been confronted with a continuous demand for sumptuous metal surfaces draped over the structure of the buildings. This is not surprising in

* Associate Professor, Dokuz Eylul University, Turkey.

1. Michael Crichton, Jurassic Park (New York: Alfred A. Knopf, 1990), 260.

https://doi.org/10.30958/aja.3-3-2

doi=10.30958/aja.3-3-2 
light of the fact that adapted technologies allow contemporary architects to build just about anything imaginable. Inevitably computer plays an important role in the realization of these billowing surfaces. And yet virtuosity in the sense of technical mastery is necessary for building these surfaces. What seems to be neglected in the current discourse is that a certain display of technical virtuosity - virtuosity for its own sake - is taken for granted in contemporary architecture. This paper explores the resemblances between the special effects of the blockbuster films and the technological advances of the current practice of architecture. It argues that blockbuster science-fiction films in which the whole aim is to impress the viewer has a partial counterpart in the ambition of many contemporary architecture. The focus is restricted to the way in which draped surfaces have taken shape within the recent projects of Los-Angeles based architect Frank Gehry. However, the highly sympathetic monographs on Gehry have not given any particular attention to his emphasis on virtuosity achieved through incorporating unprecedented silver-steel draped surfaces in one's everyday life. Here, it is argued on a similar affinity between the cinematic effects of science-fiction films and Gehry's Jay Pritzker Pavilion in the Millenium Park, Chicago as an example of the present problematic state of architecture.

\section{The Advances in Computer Technologies}

It is no coincidence that 'blockbuster architecture' granting the virtuoso draping of the cladding over the structure was born in the early 1990's through the advances in computer technologies. The fascination with draped surfaces coincided with the advances in new manufacturing technologies made possible by the computer revolution. The developments in computer-aided design (CAD) and computer-aided manufacturing (CAM) played an important role in allowing the production and construction of complex forms within a reasonable budget. $^{2}$ This reassertion of the importance of the methods of construction derives in part from David Leatherbarrow and Mohsen Mostafavi's argument in Surface Architecture: 'In contemporary architecture, the process and methods of construction play an increasingly important role in the development and realization of many projects. ${ }^{3}$ The CATIA software (Computer Aided Three-Dimensional Interactive Application), used in Frank Gehry's office, gives precise mathematical descriptions of the intricate curves and allows not only the conceiving, but also the developing and manufacturing of the components of the building. CATIA was first developed for the automobile and aerospace industries and it has been in use for the last twenty years, before it was used in Gehry's office. In relation to this, Branko Kolorevic observed that 'the building industry was among the last to change and adopt new

2. See Branko Kolarevic, Introduction to Architecture in the Digital Age: Design and Manufacturing, ed. Branko Kolarevic (New York: Spon Press, 2003).

3. David Leatherbarrow and Mohsen Mostafavi, Surface Architecture (Cambridge, Mass.: The MIT Press, 2002). 
technologies. ${ }^{4}$ Also, one has to remember that software like Softimage, Alias, and Maya used by architects and students in architectural schools were actually developed to meet the demand for special effects in the film industry.

The outcome of Gehry's first use of this technology is the large fish sculpture in the Olympic Village in Barcelona (1989) whose components were manufactured from digital files (Figure 1). In relation to the programs used in film animation, described above, the critic Hal Foster makes an analogy between Gehry's fish sculpture and the dinosaurs in Jurassic Park. ${ }^{5}$ Apart from Foster's account of formal resemblance, I would like to draw attention to another aspect of blockbuster architecture in relation to Jurassic Park - a film brought the dinosaurs into life through the technological capabilities of computer graphics, as mentioned earlier. This 1993 the science-fiction film of the American director Steven Spielberg made a revolution in the special effects technology: Old motion control cameras had to give their place to computer graphics software and renderings. And yet, the film's success depended on the computer-generated special effects. Something similar can be said of Gehry's fish sculpture, which presents the first incorporation of digital technologies into the production of its components.

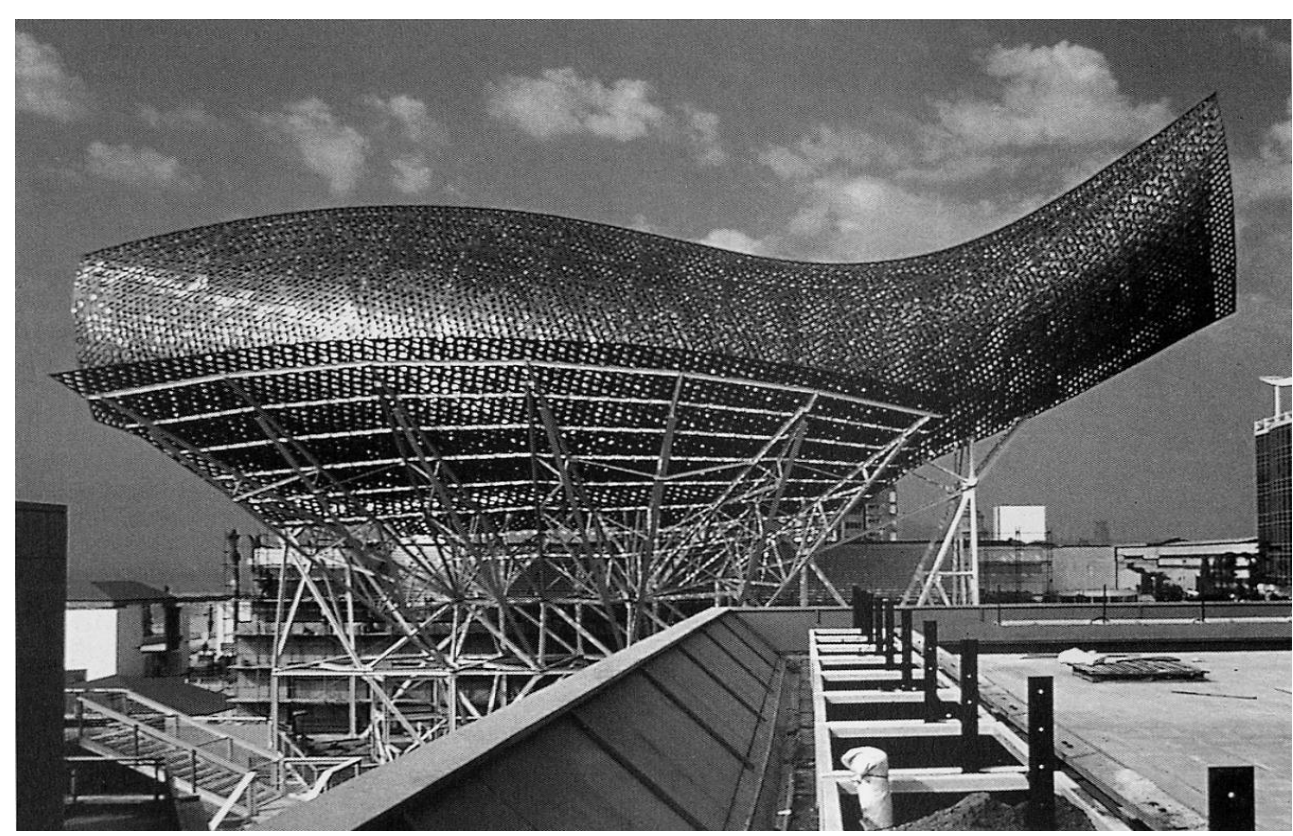

Figure 1. Gehry Partners, Fish sculpture, Olympic Village, Barcelona, 1989 Source: Shannon Dorff.

The traditional plan-section drawings gave their place to digital threedimensional models through which the components of the fish sculpture were produced. That is probably why the orthogonal drawings do not appear in Gehry's colorful monographs. One can imagine the difficulty of describing the

4. Kolarovic, Architecture in the Digital Age, 6.

5. Hal Foster, "Master Builder," in Design and Crime: and Other Diatribes (London; New York: Verso, 2002), 35. 
fish by means of conventional drawings. From this structure on the group of the three - plan, elevation, and section - was no longer employed by Gehry partners since constructing blockbuster architectures from orthogonal drawings would be nearly impossible. Recalling a similar problem, Robin Evans wrote that in the Hans Scharouns's Philharmonie building in Berlin construction workers were confronted with serious difficulties in setting out the foundations. ${ }^{6}$ Only after taking large-scale sections at very closely spaced intervals across the breadth of the building, workers were able to continue to build. $^{7}$ To be able to describe Gehry's fish in sections, perhaps, one would need to chop the building into billions of thin slices. Instead of this burdensome task, Gehry's office employed a digital three-dimensional model as the sole source of information for the entire project.

Yet, another similarity can be found in the new union between computer engineers and filmmakers who jointly produce the blockbuster science fiction films. That would be in the form of special-effects companies such as Digital Domain, Dream Works, Industrial Light and Magic (ILM), and Rhythm \& Hues. ${ }^{8}$ Correspondingly, through blockbuster architecture the architectural environment witnessed an alliance between architects and software engineers, since blockbuster architecture shares a similar delight in creating spectacles that are reliant upon computer technology.

\section{Spielberg and Gehry}

Blockbuster science-fiction films of the 1990s, such as Jurassic Park, Terminator 2: Judgement Day, Independence Day, have much in common with blockbuster architecture. Rather than centering the film on a story, the contemporary effects-cinema emphasizes display, exhibitionism and spectacle 'pushing technology to new limits, and for the first time in history, showcasing science fiction and the science fiction aspects of film technology in the multimillion blockbuster format." I believe in both blockbuster architecture and contemporary science-fiction films there is a common concern with exhibitionism, virtuosity and spectacle. Both share a fascination with the

6. Robin Evans, The Projective Cast: Architecture and Its Three Geometries (Cambridge, Mass.: The MIT Press, 1995), 120-21.

7. Hans Scharouns's Philharmonie Hall is not the only example. The difficulty of representing architecture in a conventional way (by plans, sections and elevations) already exists in the Baroque architecture; more recently, it can be found in the work of Antonio Gaudi, Rudolf Steiner or Hundertwasser. This architecture was not born with the use of the computer and does not necessarily imply the use of special software.

8. Angela Ndalianis, Neo-Baroque Aesthetics and Contemporary Entertainment (Cambridge, Mass.: The MIT Press, 2004), 181.

9. Ibid, 184. Of course Jurassic Park is not the first film whose narrative depends on its special effects. Several films have been developing the expertise in the use of special effects, the first movie of the Star Wars saga (Episode IV - A New Hope), written and directed by George Lucas, in 1977, like Back to the Future (1985) and Who Framed Roger Rabbit (1988) both directed by Robert Zemeckis could be early examples. 
previously unimaginable. Blockbuster architecture shows the desire to create previously un-buildable buildings; whereas contemporary science fiction films deal with creating previously imperceptible realities. ${ }^{10}$ But both are only made possible as a result of a computer technology and thus display the advances and capabilities of this technology.

The resemblances do not end here. Spielberg and Gehry have much in common. The onscreen illusions in Jurassic Park lure the audience into a game of perception inviting them to marvel at the realistic portrayal of extinct dinosaurs. The vviewers of Jurassic Park find themselves in an ambiguous relationship with regard to the technologically produced spectacle similar to those evoked by the technological advances enabling the construction of blockbuster architecture. Both create an illusion in inviting the spectator to recognize the spectacle and simultaneously to be astonished at the methods employed to construct it. Both aim to captivate the viewer by the seductive motions of technologically produced spectacles. The problematic consequences of illusionistic spectacle were already discussed by Guy Debord in 1968: 'The spectacle obliterates the boundaries between self and world by crushing the self-besieged by the presence-absence of the world and it obliterates the boundary between true and false by driving all lived truth below the real presence of illusion ensured by the organization of appearance. ${ }^{11}$

In her discussion of science fiction cinema Angela Ndalianis states that special effects in science fiction films beyond their narrative function are the means of unveiling technological advances. ${ }^{12}$ Thus, the primary attraction of Jurassic Park is not the genetically engineered dinosaurs, but the computer engineered dinosaur effects. ${ }^{13}$ And yet, 'underneath the technical virtuosity is a standard chase film, and director Steven Spielberg does little to elevate it dramatically. ${ }^{14}$ The movie had bad reviews such as 'Spielberg skipped the storytelling part and head straight for technical virtuosity' or 'the movie often feels exciting, but afterwards you're left with nothing of consequence to consider. ${ }^{15}$ This has a counterpart in the ambition of blockbuster architecture, which merits attention. The main attraction in blockbuster architecture is not the qualities of space, but the computer generated sumptuous metal surfaces. They are the means of unveiling technological advances in the current practice of architecture. They have a great role to inform the public in terms of the recent construction technologies.

10. Blockbuster architectures show the desire to create previously un-buildable buildings but this desire has been an important part of architectural history: See the drawings of ÉtienneLouis Boullée (1728-1799), Antonio Sant'Elia (1888-1916), the Japanese Metabolists or the Archigram group. But none of these works are made possible as a result of a computer technology and thus display the advances and capabilities of this technology. In that reasoning, they are not called blockbuster architectures.

11. Guy Debord, Society of the Spectacle (New York: Zone Books, 1994), 219.

12. Ndalianis, 2004, 186.

13. Ndalianis, 2004, 166.

14. Leonard Klady, “The Lost World: Jurassic Park,” Daily Variety 25 (1997).

15. "While it pushed special effects to a completely new level and awed its audiences, it lacked the great storytelling." See Gary Johnson, "The Lost World, Movie review," Images 3 (1997). 


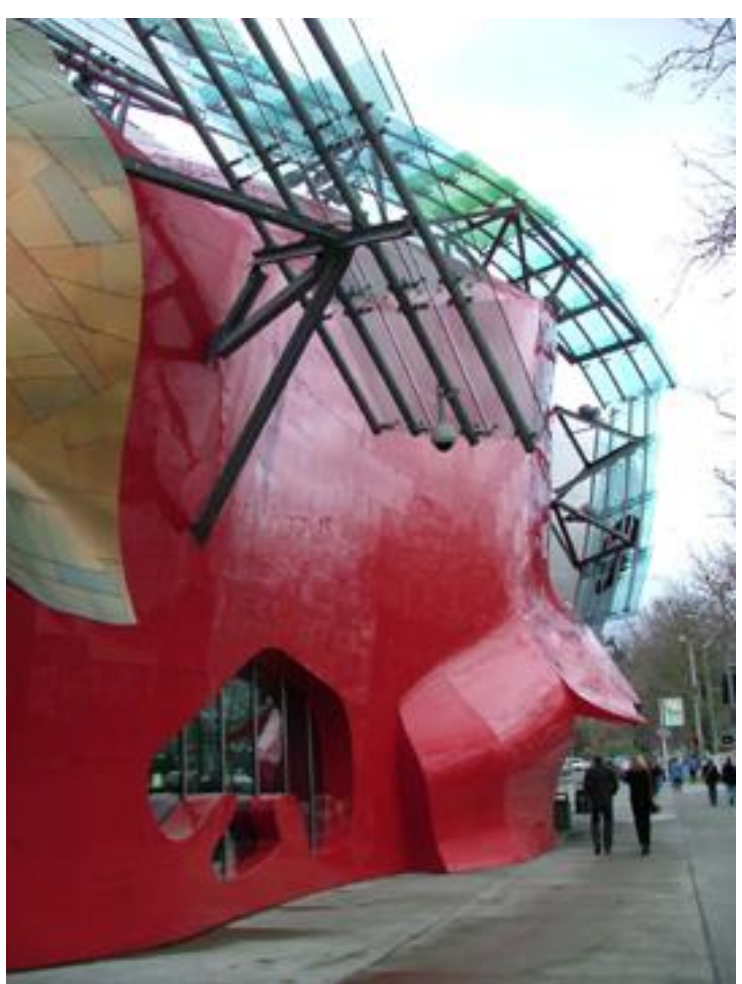

Figure 2. Gehry Partners, Experience Music Project, Seattle Source: Author.

\section{The Unlimited Budget}

The affinities do not end here. 'Just 15 years ago, a big tent-pole film might have costed $\$ 50$ million, and 10 percent would be visual effects,' says Jim Morris, the president of Industrial Light and Magic, 'now it is very common to have a $\$ 150$ million budget and a third of that is going to visual effects. ${ }^{16}$ A similar statement may be made regarding Gehry's Experience Music Project in Seattle (Figure 2). It provides an opportunity to consider the recent relationship between a building's structure and its formal expressions. Kenneth Frampton pointed out in the closing chapter of his Studies in Tectonic Culture that 'with the transition from a load bearing wall to skeleton-frame construction, the amount [of budget] devoted to the basic structure has dropped from around 80 percent in former times to some 20 percent today. Conversely, the amount allocated to lightweight partitioning has risen from 3 to 20 percent, thereby leaving around 12.5 percent to be devoted to the building envelope. ${ }^{17}$ In the EMP (which was built almost ten years after the publication of Studies in Tectonic Culture) the primacy of the envelope is apparent since only 13 percent

16. Jim Morris quoted in Devin Gordon, "Polar Expedition,” Newsweek 25 (2004), 72.

17. Kenneth Frampton, Studies in Tectonic Culture: The Poetics of Construction in Nineteenth and Twentieth Century Architecture, ed. John Cava (Cambridge, Mass.: The MIT Press, 1995), 381. 
of the budget was spent for the steel and concrete structures versus 35 percent for the building's custom-made exterior envelope. This is surely an indicative of the importance attached to the exterior surface. ${ }^{18}$

Looking at Gehry's architecture, what one sees is the display of extravaganza, impetuousness, and technological virtuosity. But, there is another thing that exists behind the glossy surface, the unlimited budget of the client. This raises a number of critical issues. Perhaps the most obvious of these is that the blockbuster architecture requires rich clients who are able to afford it, such as Lilian Disney, the widow of Walt Disney, or Paul Allen, the cofounder of Microsoft, or the Guggenheim family, to mention only a few. Similarly, rich clients seem to prefer Gehry's work, as they are able to represent their wealth through blockbuster architecture. In the Walt Disney Concert Hall, for instance, when the 50 million dollars of Lillian Disney were not enough for completing the construction, the contribution of the donors saved the life of the building. ${ }^{19}$ The donor names were etched onto floors and walls in letters proportionate in size to the amount they gave. The most generous donors had their names given to the parts of the building: hence, the Eli Broad auditorium, the Henri Mancini family stairway, Costanza restroom, and so forth.

\section{The Bilbao Effect}

The undeniable fact is that each new science fiction film competes with its predecessor. Each new blockbuster appears with the promise of showing audiences something they have never seen before: As Ndalianis stated, 'Each virtuoso performance attempts to outshine that of its predecessor. ${ }^{20}$ In the films like The Lost World: Jurassic Park II and Jurassic Park III - the sequels of Jurassic Park - the task was creating the dinosaurs much better than the ones in the first film. They should be more credible, breathtaking and frightening. Yet the Jurassic Park sequels received harsh criticism from the movie reviewers. This has also a counterpart in the ambition of blockbuster architecture. In fact, this is a debate among architectural critics whether Gehry would ever be able to outshine the Guggenheim Museum in Bilbao, Spain. ${ }^{21}$ And yet, this 'serial structure' that manifests itself in blockbuster architecture is supported by municipal authorities around the world. The so-called Bilbao effect captured the attention of those who want a Gehry building in their cities. Today almost every city has its own blockbuster architecture or is in the

18. Acalya Kiyak, "Rock and Liberty: Experience Music Project by Frank Gehry," On Site Review 9 (2003): 20-1.

19. Aaron Betsky, "Frank Gehry's Walt Disney Concert Hall - his Masterpiece Dances with Death," Architectural Record 183, no. 10 (1995): 23.

20. Ndalianis, 2004: 185.

21. Gevork Hartoonian, "Frank Gehry: Roofing, Wrapping, and Wrapping the Roof," Journal of Architecture 7, no. 1 (2002): 1-31. 
process of getting one. The 'serialism' of blockbuster architecture appears to reject any notion of regionalism: it arrogantly dismisses the external conditions of the site. Its indifference to local materials and modes of construction makes it like the black monolith in 2001: A Space Odyssey - a stranger in any location.

In addition to the 'serialism' of blockbuster architecture there is another equally important issue: character - a term virtually nonexistent in the current architectural discussions. The concept of character - whether there is a proper relationship between the purpose of a building and its appearance - became dominant in the architectural debates in the early eighteenth-century. Besides its modern usage in English, in the context of architectural theory, caractère refers to the outward manifestation of the inner nature of the building. The eighteenth-century French architect Germain Boffrand's treatise, Book of Architecture (1745), presents an aesthetics of character derived from classical rhetoric. ${ }^{22}$ Relying on Horace's Art of Poetry, Boffrand applied the principles of classical rhetoric to architectural design: 'Architecture, although its object may seem to be no more than the use of material, is capable of a number of genres that bring its component parts to life, so to speak, through the different characters that it conveys to us. Through its composition a building expresses, as if on a stage, that the scene is pastoral or tragic; that this is a temple or a palace, a public building destined for a particular purpose or a private house. By their planning, their structure and their decoration, all such buildings must proclaim their purpose to the beholder. ... The same is true of poetry: this, too, has its different genres, and the style of one does not suit another. ${ }^{23}$

Boffrand explains later, 'Decorum, or what is fitting or appropriate, is a key concept in rhetoric: without a sense of what fits the subject, the audience and the occasion, the orator has no chance of establishing contact with his listeners and persuading them of his views. ${ }^{24}$ A speaker, for example, cannot use the same rhetoric in a matrimonial ceremony and a funeral. Today classical rhetoric is not a central part of our education or lives. However, what Boffrand addressed in his formulation of expression in architecture is a central problematic issue in Gehry's oeuvre. Whether it is a library, a winery, or, just a residence, the silver-steel envelope is draped on the structure in the same fashion thus making the scene always 'tragic'. That is probably why Gehry's buildings, which have been variously described as Deconstructivist, Postmodern, Neo-avant-garde, etc., evade easy classification. He must be taking pleasure in creating what can be called a 'Gehry character.' As a matter of fact, this tendency is not new. One can cite Richard Meier's or Peter

22. Germain Boffrand, Book of Architecture: Containing the General Principles of the Art and the Plans, Elevations and Sections of Some of the Edifices Built in France and in Foreign Countries, trans. D. Britt, ed. Caroline van Eck (Aldershot, England; Burlington, VT: Ashgate, 2002).

23. Boffrand, Book of Architecture, 8.

24. Caroline van Eck, "Introduction," in Germain Boffrand, Book of Architecture: Containing the General Principles of the Art and the Plans, Elevations and Sections of Some of the Edifices Built in France and in Foreign Countries, trans. David Britt, ed. Caroline van Eck (Aldershot, England; Burlington, VT: Ashgate, 2002), xix. 
Eisenman's oeuvre as an example. As Dalibor Vesely wrote, 'The twentiethcentury witnessed many attempts to treat architecture as a culturally emancipated discipline, free of all references to the natural world. ${ }^{, 25}$

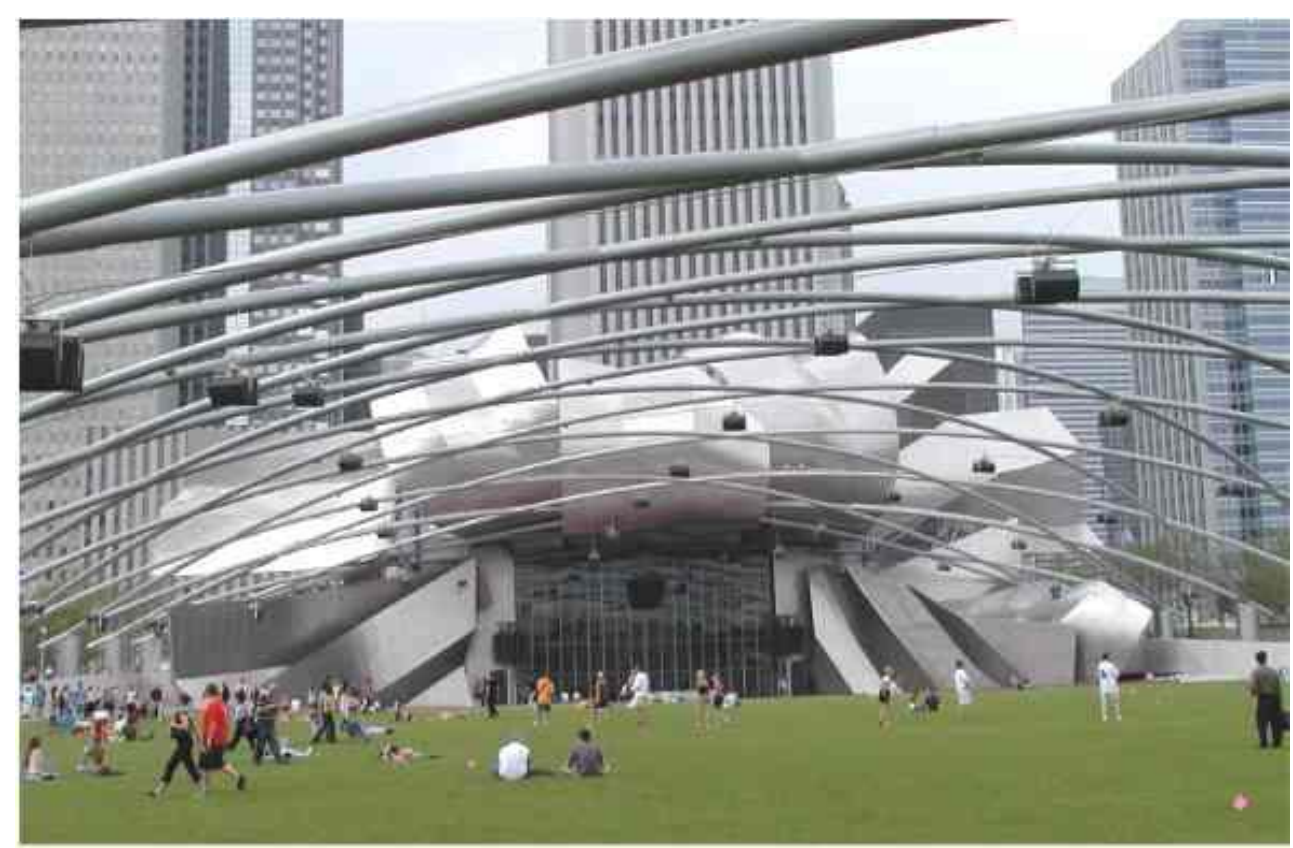

Figure 3. Gehry Partners, Jay Pritzker Pavilion, Chicago

Source: Author.

\section{Welcome to the Millenium Park!}

The Jay Pritzker Pavilion in Millennium Park is one of the recently built Gehry tour de force (Figure 3). It is in the heart of downtown Chicago on Michigan Avenue between Randolf and Monroe Streets. It is easily accessible, and open to all Chicagoans and tourists. The Pritzker Pavilion seats 4000 people in stadium seating and 7000 on the lawn. Since its opening in July 2004, it is one of the most popular free attractions in Chicago besides the Navy Pier and Lincoln Park Zoo. This outdoor concert hall is a must-see experience for the tourists whether there is a concert going on or not. The brushed stainless steel ribbons that frame the stage opening succeed in attracting millions and transforming the Pavilion into a 'city attraction.' Such transformation raises questions: What then are the objects of the spectacle? What is being presented? The answer to these questions is already present in the sign placed in front of the building: 'The Jay Pritzker Pavilion'. However, it seems that what is displayed is not the Pavilion itself since the draped surface has become a display object, an element of expression. It is the unsettling shimmering stainless steel that is the pure attraction, the surface without anything behind it,

25. Dalibor Vesely, Architecture in the Age of Divided Representation: The Question of Creativity in the Shadow of Production (Cambridge, Mass.: The MIT Press, 2004), 356. 
and in Gadamer's words 'pure expression. ${ }^{26}$ And yet, in Gehry's hands, the emphasis on virtuosity serves to transform the building and makes it a site of conspicuous display, thus turning into 'architecture of a gigantic-drapery. ${ }^{, 27}$ Jay Pritzker Pavilion is not alone in the Millennium Park. The Crown Fountain by Jaume Plensa and Anish Kapoor's Cloud Gate sculpture are alone enough to call the Park an amusement Park.

Similar conceptions are in operation in the Jurassic Park and the Millenium Park. Like the dinosaur pictures in the Jurassic Park souvenir shops in Los Angeles and Orlando, Gehry's sketches of the Jay Pritzker Pavilion are already on the key chains, t-shirts and other items of the Chicago gift shops. Much like the effects astonishing the audience with their level of expertise and with the technologies' ability to produce convincing illusions, Gehry depends on playful virtuosity to send the visitor out of the park grinning with delight.

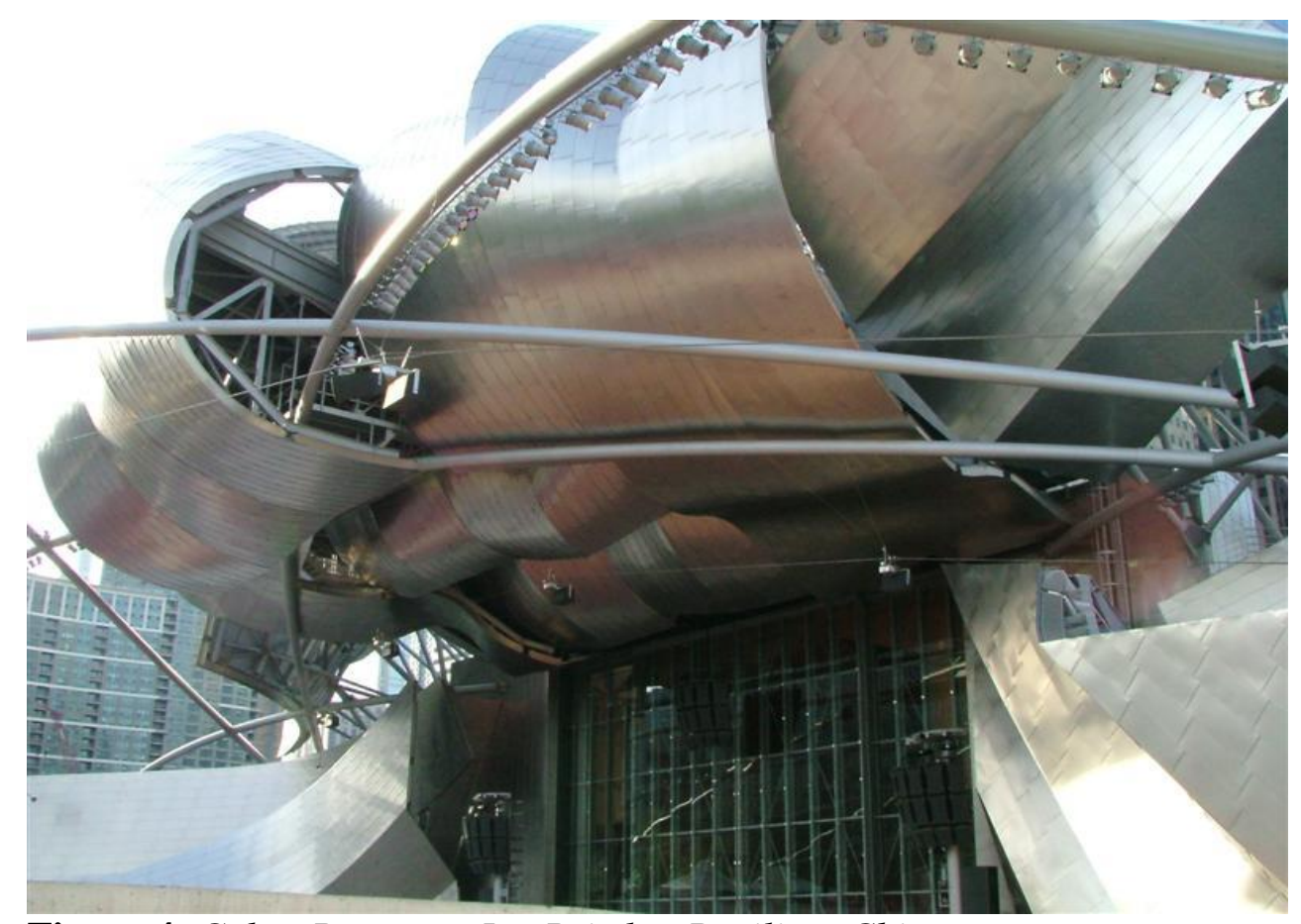

Figure 4. Gehry Partners, Jay Pritzker Pavilion, Chicago

Source: Author.

One peculiar aspect in the construction of the Pavilion that needs to be mentioned is the employment of custom-made elements, which represents an important change in the logic of building production (Figure 4). The use of custom-made pieces is one of the elements that makes Gehry's architecture unique, but at the same time makes it troubling. That is because an architectural drapery is not made of cloth but of metal, and not just one piece

26. Hans-George Gadamer, The Relevance of the Beautiful and Other Essays, trans. N. Walker. Cambridge; New York: Cambridge University Press, 1986.

27. Acalya Allmer, "The Architecture of Gigantic Drapery: The Richard B. Fisher Center for Performing Arts, Bard College," ARQ: Architectural Research Quarterly 11, no. 3-4 (2007): 265-275. 
but many pieces, each of which is uniquely tailored, cut, bent, and folded on site to fit into the complex shapes of the intended surfaces. The CATIA software allows the three-dimensional forms to be developed into twodimensional flat shapes. Consider the time, energy, and amount of money spent in draping the metal shingles over the structure. Given the materiality and weight of the building, rendering of a drapery is not an easy task. Nonetheless, it becomes a vehicle for displaying technological virtuosity. From the Guggenheim Museum in Bilbao, Spain (1997), to the Jay Pritzker Pavilion in Millennium Park in Chicago (2004), there is an apparent change in the surface treatment. The enveloping surface wrapping around the building, as in Bilbao, became continually (but unexpectedly) interrupted or broken in Gehry's later projects such as the Millennium Park pavilion. This frayed characteristic of the building's surface reveals the thinness of the surface, thus exposing the artificiality of his gesture. The consequence of this series of interruptions on the metal surface is the frayed and torn drapery, demanding the attention of the viewer and aspiring to the status of an autonomous sculptural object.

In short, blockbuster architecture finds its realization in its exploitation of the latest technological advances. Especially in its current manifestation by Frank Gehry, blockbuster architecture takes pleasure in displaying the technological capabilities of contemporary architecture thus leaving the spectator in a state of wonder at the skill and technical mastery that lies behind its construction. In both instances - blockbuster architecture and contemporary science-fiction cinema - computers are used to induce wonder, though in different ways. And yet, the question aroused in the viewer is the same: How did they do that?

\section{Bibliography}

Allmer, Acalya. "The Architecture of Gigantic Drapery: The Richard B. Fisher Center for Performing Arts, Bard College." ARQ: Architectural Research Quarterly 11, no. 3-4 (2007): 265-275.

Betsky, Aaron. "Frank Gehry's Walt Disney Concert Hall - his Masterpiece - Dances with Death." Architectural Record 183, no. 10 (1995): 23.

Boffrand, Germain. Book of Architecture: Containing the General Principles of the Art and the Plans, Elevations and Sections of Some of the Edifices Built in France and in Foreign Countries. Translated by D. Britt. Edited by C. van Eck. Aldershot, England; Burlington, VT: Ashgate: 2002.

Crichton, Michael. Jurassic Park. New York: Alfred A. Knopf, 1990.

Debord, Guy. Society of the Spectacle. New York: Zone Books, 1994.

Evans, Robin. The Projective Cast: Architecture and Its Three Geometries. Cambridge, Mass.: The MIT Press, 1995.

Foster, Hal. Design and Crime: and Other Diatribes. London; New York: Verso, 2002.

Frampton, Kenneth. 1995. Studies in Tectonic Culture: The Poetics of Construction in Nineteenth and Twentieth Century Architecture. Cambridge, Mass.: The MIT Press. 
Gadamer, Hans-George. "The Relevance of the Beautiful and Other Essays." Translated by N. Walker. Cambridge; New York: Cambridge University Press, 1986.

Gordon, Devin. "Polar Expedition.” Newsweek 25 (2004).

Hartoonian, Gevork. "Frank Gehry: Roofing, Wrapping, and Wrapping the Roof." Journal of Architecture 7, no. 1 (2002): 1-31.

Johnson, Guy. "The Lost World, Movie review." Images 3 (1997).

Kiyak, Acalya. "Rock and Liberty: Experience Music Project by Frank Gehry." On Site Review 9, no. 20-1 (2003).

Klady, Leonard. "The Lost World: Jurassic Park.” Daily Variety 25 (1997).

Kolarovic, Branko. Introduction to Architecture in the Digital Age: Design and Manufacturing. Edited by B. Kolorevic. New York: Spon Press, 2003, 1-10.

Leatherbarrow, David and Mohsen Mostafavi. Surface Architecture. Cambridge, Mass.: The MIT Press, 2002.

Ndalianis, Angela. Neo-Baroque Aesthetics and Contemporary Entertainment. Cambridge, Mass.: The MIT Press, 2004.

van Eck, Caroline. "Introduction." In Book of Architecture: Containing the General Principles of the Art and the Plans, Elevations and Sections of Some of the Edifices Built in France and in Foreign Countries. Edited by G. Boffrand. Aldershot, England; Burlington, VT: Ashgate, 2002, xi-xxvi.

Vesely, Dalibor. Architecture in the Age of Divided Representation: The Question of Creativity in the Shadow of Production. Cambridge, Mass.: The MIT Press, 2004. 